\title{
Shear Strength Reduction Factor of Prestressed Hollow-Core Slab Units Based on the Reliability Approach
}

\author{
Hae-Chang Cho, ${ }^{1}$ Min-Kook Park, ${ }^{1}$ Hyunjin Ju, ${ }^{1}$ Jae-Yuel Oh, \\ Young-Hun Oh, ${ }^{2}$ and Kang Su Kim ${ }^{1}$ \\ ${ }^{1}$ Department of Architectural Engineering, University of Seoul, 163 Seoulsiripdae-ro, Dongdaemun-gu, \\ Seoul 02504, Republic of Korea \\ ${ }^{2}$ Department of Medical Space Design \& Management, Konyang University, 158 Gwanjeodong-ro, Seo-gu, \\ Daejeon 35365, Republic of Korea \\ Correspondence should be addressed to Kang Su Kim; kangkim@uos.ac.kr
}

Received 10 February 2017; Revised 9 May 2017; Accepted 13 June 2017; Published 17 July 2017

Academic Editor: Paulo M. S. T. De Castro

Copyright (C) 2017 Hae-Chang Cho et al. This is an open access article distributed under the Creative Commons Attribution License, which permits unrestricted use, distribution, and reproduction in any medium, provided the original work is properly cited.

\begin{abstract}
This study investigated the shear design equations for prestressed hollow-core (PHC) slabs and examined the suitability of strength reduction factors based on the structural reliability theory. The reliability indexes were calculated for the shear strength equations of PHC slabs specified in several national design codes and those proposed in previous studies. In addition, the appropriate strength reduction factors for the shear strength equations to ensure the target reliability index were calculated. The results of the reliability index analysis on the ACI318-08 equation showed that the shear strengths of the members with the heights of more than 315 mm were evaluated to be excessively safe, whereas some members with low depths did not satisfy the target reliability index.
\end{abstract}

\section{Introduction}

The prestressed hollow-core (PHC) slabs are made in the form of hollow sections with a circular or elliptical shape, as shown in Figure 1, to make them lighter and maximize the sectional efficiency. The prestress is commonly introduced to the PHC slabs by the placing of prestressing tendons, which leads them to have excellent flexural resistance. In addition, they have been widely used as a lightweight floor structural system in Europe and North America due to their excellent economic efficiency and constructability [1-3]. However, since the PHC slab members are typically formed by extruder machines that cast concrete while moving in the longitudinal direction of the members, it is very difficult to place shear reinforcements which are to be placed in the vertical direction. Moreover, the PHC slabs have thin webs due to the hollow-cores inside, and thus their shear strengths are typically dominated by the web-shear strength at the ends of the members. The method of enhancing their shear strength is truly very limited, compared to what can be done to enhance their flexural strengths, for which their member strengths are governed by the web-shear strength in most cases [2,3]. In particular, the previous experimental studies $[1,3]$ reported that, for the PHC slabs with the depths of greater than $315 \mathrm{~mm}$ (12.5 in.), the shear strengths were somewhat overestimated by the web-shear strength specified in ACI318-05. On that basis, the shear provision in ACI31808 was substantially revised to reduce the shear strength of the PHC slabs greater than $315 \mathrm{~mm}$ depth with no minimum shear reinforcement by half [3-6]. As mentioned by $\operatorname{Im}$ [7] and Palmer and Schultz $[6,8]$, however, the revised shear provision can provide very conservative shear strengths for the PHC slabs thicker than $315 \mathrm{~mm}$, and it can thus serve as a limiting factor for their wide applications. Therefore, more detailed analyses and deep examinations on the shear strengths of the PHC slabs are necessary. In the authors' previous study [9], the shear strength equations in the current design codes $[4,5,10-13]$ and by a research group [14] were examined in detail comparing to the experimental results of the PHC slab members collected from literature. Then, they 

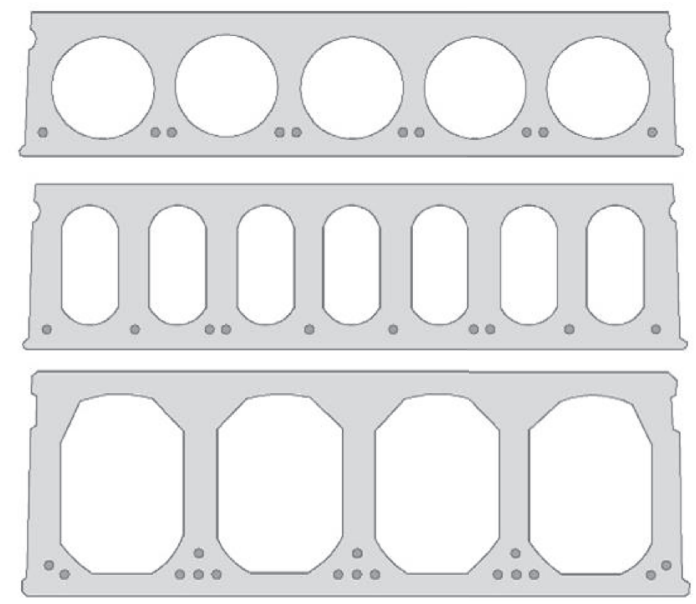

Figure 1: Various types of prestressed hollow-core slabs.

proposed an equation to calculate the web-shear strengths of the PHC slabs which is simple but provides a proper margin of safety.

In the design codes, based on the ultimate strength design approach, the design strength $\left(\phi R_{n}\right)$ is calculated by multiplying the nominal strength $\left(R_{n}\right)$ of the member and the strength reduction factor $(\phi)$ that is less than 1 , depending on the importance and failure mode of the member to take into account the variability of materials and dimensions, the construction errors, the uncertainties of code equations, and so on. Macgregor et al. [15] determined the strength reduction factor $(\phi)$ by performing structural reliability analyses on the experimental results available at that time. In the current ACI 318 design code (2014) [16], however, the shear strength reduction factor is 0.75 for both reinforced concrete $(\mathrm{RC})$ and prestressed concrete (PSC) members even though the construction errors and the uncertainties of the code equations for the RC and PSC members are not the same. In particular, Lee et al. [9] reported that the web-shear strength equation for PSC members overestimated the shear strengths of the PHC slabs with the heights of less than $315 \mathrm{~mm}$ (thin PHC slabs, hereafter) as well as those of greater than $315 \mathrm{~mm}$ (thick PHC slabs, hereafter). Thus, it is necessary to reexamine the current reduction factor for the shear strengths of $\mathrm{PHC}$ slabs. In this regard, this study examined the suitability of the shear strength reduction factor of 0.75 specified in the current ACI 318 design code (2014), based on the structural reliability analysis on the experimental results of the $\mathrm{PHC}$ slabs collected from literature including the authors' previous study.

\section{Web-Shear Strength}

The shear failures of PSC members without shear reinforcements are generally divided into the web-shear and flexuralshear failures [20-22]. The shear failure of PHC slabs that have a thin web due to the hollow-cores in the section is dominated by web-shear strength in most cases [3, 6-9, 23$25]$. In most design codes $[4,5,11]$, two assumptions are

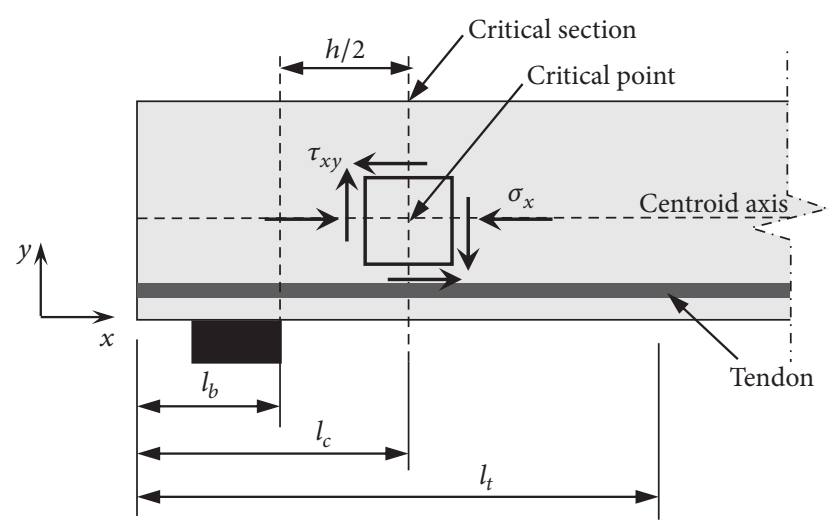

FIGURE 2: Description of transfer length $\left(l_{t}\right)$, bearing length $\left(l_{b}\right)$, and critical section $\left(l_{c}\right)$.

introduced to simplify the calculations of web-shear strength; as shown in Figure 2, the critical section is located at a certain distance $\left(l_{c}\right)$ away from the support, and the vertical normal stress $\left(\sigma_{y}\right)$ at the centroid of the section is negligible. Then, the shear strength $\left(\tau_{x y}\right)$ and the longitudinal stress $\left(\sigma_{x}\right)$ at the centroid axis of the critical section can be represented as follows:

$$
\begin{gathered}
\sigma_{x}=\alpha \frac{f_{p e} A_{p s}}{A_{c}}, \\
\tau_{x y}=\frac{S}{b_{w} I_{g}} V_{y},
\end{gathered}
$$

where $\alpha$ is the ratio of the prestress at the critical section to the fully effective prestress of the strands, which can be estimated as the distance $\left(l_{c}\right)$ from the member end to the critical section divided by the transfer length $\left(l_{t}\right)$ as shown in Figure 2. Also, $f_{p e}$ is the effective prestress, $A_{p s}$ and $A_{c}$ are the cross-sectional area of the strands and the member, respectively, $S$ is the moment of area, $I_{g}$ is the moment of inertia of gross section, $b_{w}$ is the sum of the web width, and $V_{y}$ is the shear force acting on the section. According to the theory of elasticity [26], the principal tensile stress $\left(\sigma_{1}\right)$ at the critical section can be represented as follows:

$$
\sigma_{1}=\frac{\sigma_{x}}{2}+\sqrt{\frac{\sigma_{x}^{2}}{4}+\tau_{x y}^{2}}
$$

The point at which the principal tensile stress $\left(\sigma_{1}\right)$ on the web reaches the tensile strength of the concrete $\left(f_{c t}\right)$ is considered as the shear cracking strength of the PSC member. The shear cracking strength and the shear strength of the member can be different, but they are assumed to be the same because their difference is very small especially when no shear reinforcements are placed. Therefore, by substituting (1) and (2) into $\sigma_{x}$ and $\tau_{x y}$ in (3), respectively, the web-shear strength $\left(V_{c w}\right)$ can be represented as follows:

$$
V_{c w}=\frac{I_{g} b_{w}}{S} \sqrt{f_{c t}^{2}+\alpha f_{p e} f_{c t} \frac{A_{p s}}{A_{c}}} .
$$


In Eurocode 2 [11] and FIP recommendations [12], (4) is used to calculate the web-shear strength of PSC members. Eurocode 2 also presents the web-shear strength $\left(V_{R d, c}\right)$ of PSC members in a similar form as follows:

$$
V_{R d, c}=\frac{I \cdot b_{w}}{S} \sqrt{f_{c t d}^{2}+\alpha_{l} \sigma_{c p} f_{c t d}}
$$

where $f_{c t d}$ is $\alpha_{c t} 0.7 f_{c t m} / \gamma_{c}$. Here, $\alpha_{c t}$ is a coefficient to take account of long term effects on the tensile strength and unfavorable effects depending on the patterns of applied loads, and the recommended value is 1.0 in most cases. Also, $\gamma_{c}$ is the partial safety factor for concrete, and 1.5 was used. $f_{c t m}$ is the mean value of axial tensile strength of concrete, where $0.3\left(f_{c}^{\prime}\right)^{2 / 3}$ was applied when the compressive strength of concrete $\left(f_{c}^{\prime}\right)$ is less than $50 \mathrm{MPa}$ and $2.12 \ln \left(1+\left(f_{c}^{\prime}+8\right) / 10\right)$ when $f_{c}^{\prime}$ exceeds $50 \mathrm{MPa}$. In addition, $\alpha_{l}$ is $l_{x} / l_{p t 2}$, which shall not be greater than 1.0, where $l_{x}$ is the distance of the critical section from the starting point of the transfer length (equals to $l_{c}$ ), and $l_{p t 2}$ is the upper bound value of the transfer length (equal to $l_{t}$ ), which is calculated to be $\alpha_{1} \alpha_{2} d_{b} f_{p i} / \eta_{p 1} \eta_{1} f_{c t d}$. Here, $\alpha_{1}$ is $1.25, \alpha_{2}$ is $0.19, \eta_{p 1}$ is $3.2, \eta_{1}$ is $1.0, d_{b}$ is the diameter of strands, and $f_{p i}$ is the stress of strands right after release. $\sigma_{c p}$ is the concrete compressive stress at the centroid axis due to axial loading and/or prestressing (equals to $f_{p c}$ ).

Walraven and Mercx (1983) proposed the web-shear strength $\left(V_{c w}\right)$ of PHC slabs by applying the overall reduction factor of 0.75 to Eurocode 2 equation, as follows:

$$
V_{c w}=0.75 \frac{I b_{w}}{S} \sqrt{f_{c t}{ }^{2}+\alpha_{l e} \sigma_{c p} f_{c t}},
$$

where $\alpha_{l e}$ is as follows:

$$
\alpha_{l e}=1-\left[\frac{\left(l_{t}-l_{b}\right)}{l_{t}}\right]^{2}
$$

and $f_{c t}$ is $0.05 f_{c u}+1$, and $l_{b}$ is the bearing length.

The FIP recommendation [12] suggests the web-shear strength $\left(V_{R d 12}\right)$ as follows:

$$
V_{R d 12}=\frac{I b_{w}}{S} \sqrt{f_{c t d}^{2}+0.9 \alpha \sigma_{c p} f_{c t d}} .
$$

In (5), compared to (8), the reduction factor of 0.9 was additionally considered. Also, $0.3\left(f_{c}^{\prime}\right)^{2 / 3}$ presented in the CEB-FIP Model Code [12] is used for $f_{c t d}$, and the value $\alpha_{l e}$ presented by Walraven and Mercx [14] in (7) is also applied for $\alpha$. In JSCE (2007), the web-shear strength $\left(V_{w c d}\right)$ of the prestressed member without shear reinforcements is presented as follows:

$$
V_{w c d}=\frac{f_{w c d} b_{w} d}{\gamma_{b}}
$$

where $f_{w c d}$ is $1.25 \sqrt{f_{c}^{\prime}}, \gamma_{b}$ is the member factor that is generally taken to the value of 1.3 , and $d$ is the effective member depth.
ACI318-08 and AASHTO-LRFD simplified method [10] assumes the shear stress distribution as the mean shear stress $\left(\tau_{x y, a}\right)$, as follows:

$$
\tau_{x y, a}=\frac{V_{y}}{b_{w} d_{p}} .
$$

Accordingly, the web-shear strength $\left(V_{c w}\right)$ is presented in ACI318-08 (same as ACI318-14) and AASHTO-LRFD simplified method, respectively, as follows:

$$
\begin{aligned}
& V_{c w}=\left(0.29 \sqrt{f_{c}^{\prime}}+0.3 f_{p c}\right) b_{w} d_{p}+V_{p} \\
& V_{c w}=\left(0.16 \sqrt{f_{c}^{\prime}}+0.3 f_{p c}\right) b_{w} d_{v}+V_{p}
\end{aligned}
$$

where $d_{p}$ is the distance from the extreme compression fiber to the centroid of prestressing steel, $d_{v}$ is the effective shear depth, and $V_{p}$ is the vertical component of prestressing force. However, since most of the PHC slabs without shear reinforcements fail in shear soon or right after diagonal cracks occur in the web, mostly having no flexural cracks at the end region, it is not suitable to calculate the web-shear strength by assuming the shear stress as the mean stress value of a cracked section. Therefore, in the authors' previous study [9], they considered the shear stress distribution as a parabolic shape and proposed the web-shear strength $\left(V_{c w}\right)$ as follows:

$$
V_{c w}=\left(0.29 \lambda \sqrt{f_{c}^{\prime}}+0.3 f_{p c}\right) \frac{b_{w} I}{S}+V_{p}
$$

where the web-shear strength presented in ACI318-05 was lowered as much as the ratio of the average to the parabolic shear stress; that is, $\left[I_{g} /\left(S d_{p}\right)\right]$. In addition, a more simplified version of (13) was also proposed by applying the mean value of $I_{g} /\left(S d_{p}\right)$ of the collected specimens as 0.76 , as follows:

$$
V_{c w}=\left(0.22 \sqrt{f_{c}^{\prime}}+0.23 f_{p c}\right) b_{w} d_{p}
$$

Even in the authors' previous study (Lee et al., 2014), they recommended reducing the shear strength, calculated by (14), of the PHC slab members having more than $500 \mathrm{~mm}$ depth by half to ensure a proper margin of safety.

As shown in Table 1, a total of 155 experimental data sets were collected from Lee et al. [9] and Im [7] in order to validate the accuracy and reliability of the shear strength equations of design codes or previous studies. Table 3 presents the strength ratios $\left(V_{c w, \mathrm{Cal}} / V_{c w, \text { Test }}\right)$ of the shear strengths calculated by design codes and previous researchers to the test results on the specimens collected in this study. Note that no material or strength reduction factor was applied in the calculation only to check the accuracies of their shear strengths. It seems that the web-shear strength equation of ACI318-05 provided a good accuracy with a mean of 0.955 and a COV (coefficient of variation) of 0.251. Lee et al. [9] reported, however, that the shear strength by ACI318-05 provided unsafe results for a large number of specimens as shown in Figure 3(a), and a similar observation was also made in the cases of FIP and JSCE. As shown in Figure 3(b), the 


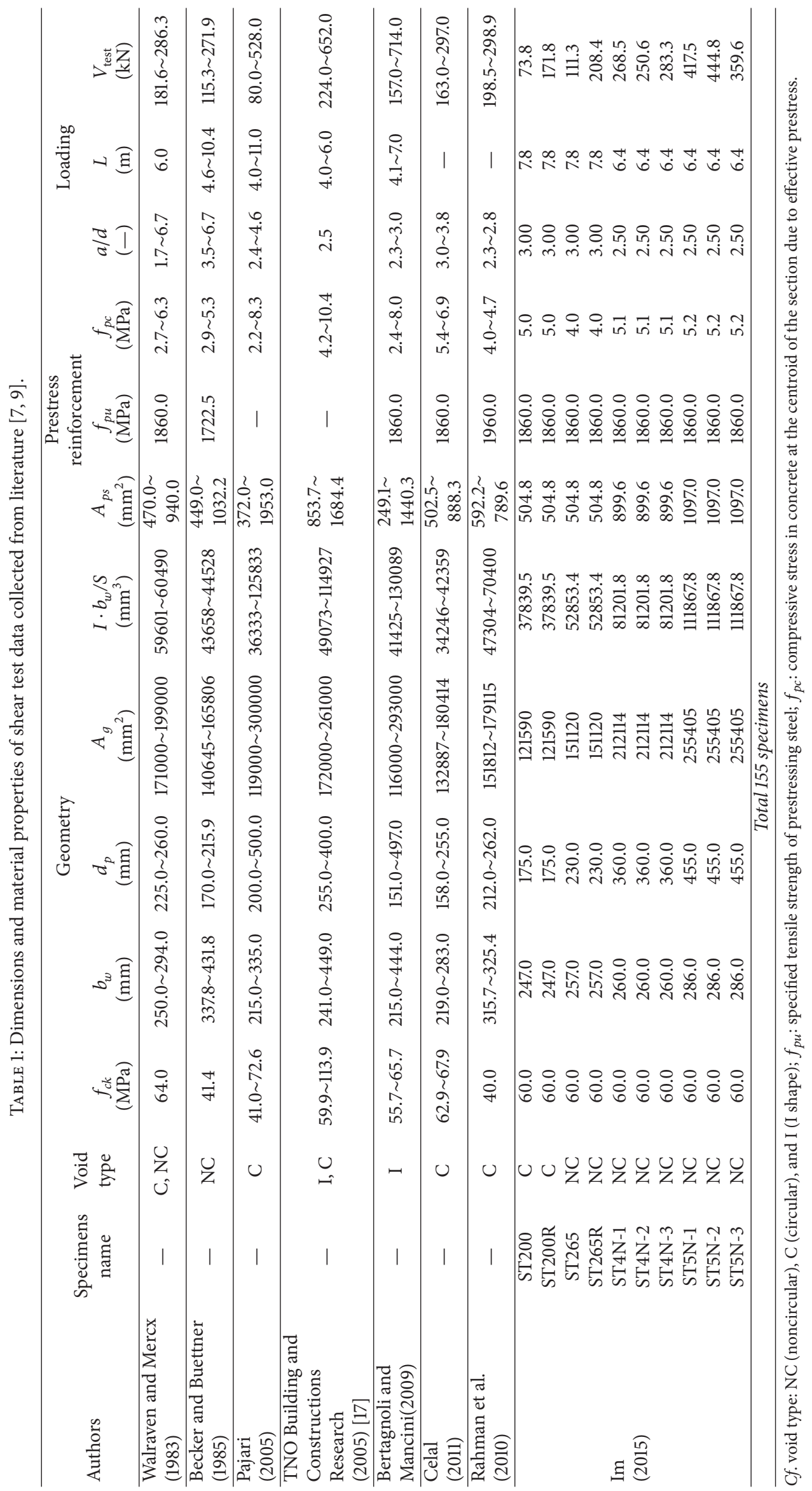



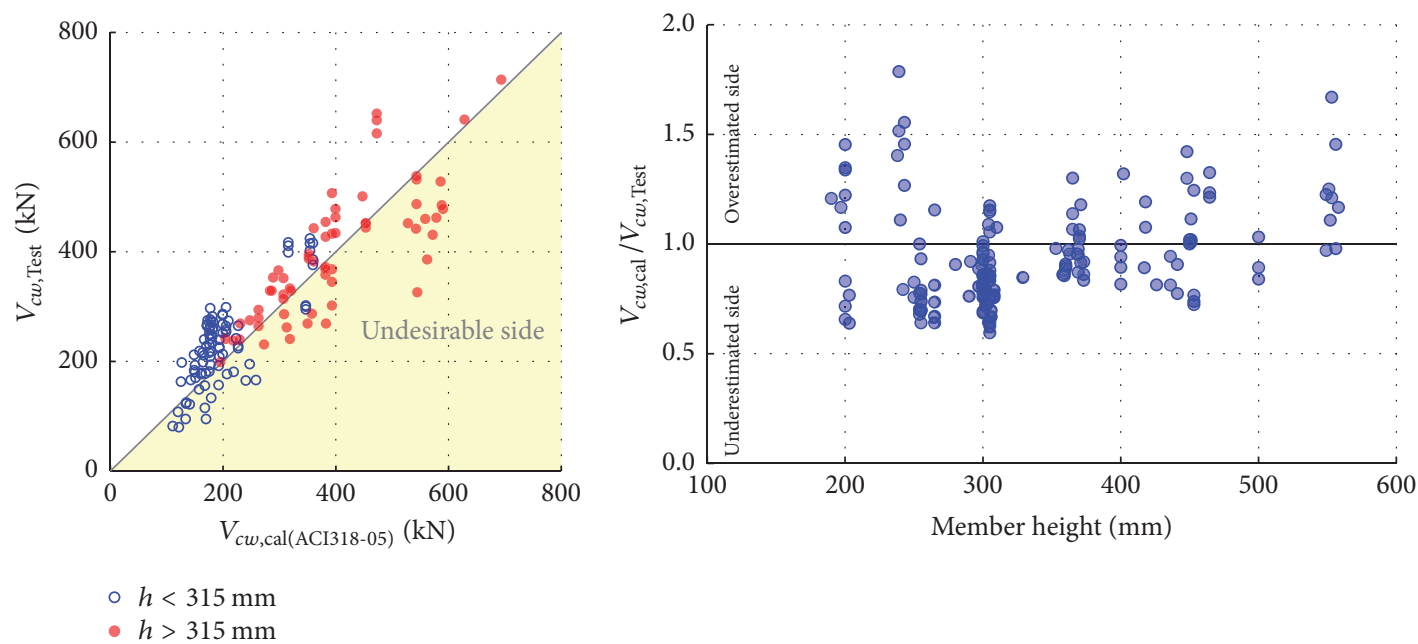

- $h>315 \mathrm{~mm}$

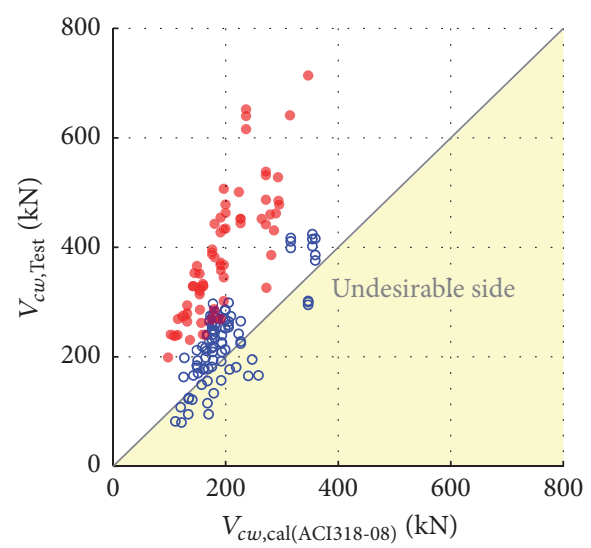

(a) $\mathrm{ACI} 318-05$

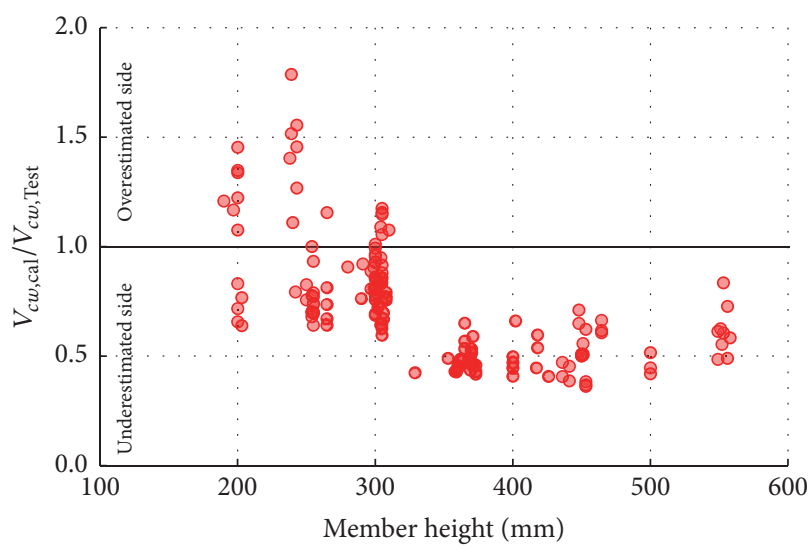

- $h<315 \mathrm{~mm}$

- $h>315 \mathrm{~mm}$

(b) $\mathrm{ACI} 318-08$

FIGURE 3: Shear strength ratios by design codes of ACI318-05 and ACI318-08.

ACI318-08, revised from ACI318-05, provided very conservative estimation on the shear strength of the PHC slabs having more than $315 \mathrm{~mm}$ depth. Compared to these shear strength equations, the proposed equations by Walraven and Mercx [14] and Lee et al. [9] showed a better accuracy, as will be examined in detail later in the section on the shear strength reduction factor for PHC slabs. In particular, the equation proposed by Lee et al. [9] is fairly easy to apply in practical design because of its simple form.

\section{Strength Reduction Factor}

Many researches have been conducted to ensure the structural safety by considering the uncertainties of structural materials and members [18, 27], which required a lot of time and efforts since they are based on the vast amount of experimental results and statistical data. Macgregor [27] collected the experimental results of reinforced concrete and prestressed concrete members, based on which they performed statistical analysis to investigate the uncertainties of the materials and members and derived the relationship between the strength reduction factor and the load factor based on the predetermined target reliability index $\left(\beta_{t}\right)$. The target reliability is an index set to ensure a certain level of safety. In general, the probabilistic approaches to evaluate the structural safety by applying the structural reliability theory $[28,29]$ are divided into three types, that is, Level I, Level II, and Level III [30]. Level III is the most accurate approach, in which numerous random values are generated through a Monte Carlo simulation based on the mean and variance of each random variable and then substituted into the limit state function to directly calculate the number of failure cases. This method requires a significantly large number of trials, which is very disadvantageous. Level II is an approximate approach that estimates the failure probability through the reliability methods such as the First-Order Reliability Method (FORM) and the Second-Order Reliability Method (SORM). The limit state function can be linearized by the FORM, and 
the reliability index is then estimated in a simple manner. The limit state function can be approximated in a quadratic form by the SORM, and the probability of failure is then estimated at the quadratic failure surface. These methods have an advantage in that the time required for analysis is relatively shorter than Level III. Level I is a method that determines the safety factor so that the reliability index $(\beta)$, based on the design strength, exceeds the target reliability $\left(\beta_{t}\right)$ [31]. The target reliability can be determined by considering the safety margin and the consequences of failure. Macgregor [27] performed statistical analysis of the relationship between the strength reduction factor and the load factor, based on which he determined $\beta_{t}$ as 3.0 to satisfy the failure probability of $0.13 \%$, and decided the load factors for the combination of dead loads, live loads, and snow loads, as follows:

$$
\begin{aligned}
& U=1.2 D+1.6 L, \\
& U=1.2 D+1.6 S, \\
& U=1.4 D,
\end{aligned}
$$

where $U$ is the factored load, $D$ is the dead load, $L$ is the live load, and $S$ is the snow load. In addition, when a wind load and earthquake load are applied, $\beta_{t}$ was set to 2.5 and 2.0, respectively, and the load combinations were determined, as follows:

$$
\begin{aligned}
& U=1.2 D+1.3 W+0.5 L, \\
& U=1.2 D+1.5 E+(0.5 L \text { or } 0.2 S), \\
& U=0.9 D-(1.3 W \text { or } 1.5 E),
\end{aligned}
$$

where $W$ is the wind load and $E$ is the earthquake load. The failure probability varies greatly depending not only on the variability of the loads but also on the failure modes of the members. For the case of shear, the differences between the actual failure loads and the member strengths calculated by code equations are relatively large, and thus it should be designed to be safer compared to the case of flexure. Therefore, Macgregor [27] proposed different strength reduction factors according to failure modes so as to satisfy $\beta_{t}$ with the load factors. In ACI318-83, the strength reduction factors were 0.85 for flexure, 0.70 for shear and torsion, and 0.70 and 0.65 for the spiral and the tied columns under compression, respectively, which were then revised a few times later up to the current version of ACI318-14.

In recent years, however, the uncertainties of the material and member strengths have been reduced with the development of material production and processing technology and structural design and construction technology. Accordingly, the design of concrete members by applying the strength reduction factors based on previous statistical data on the materials and members can lead to becoming excessively conservative, which may cause restraining economic efficiency. Nowak and Szerszen $[18,19]$ conducted a research on the strength reduction factors by setting $\beta_{t}$ to 3.5 based on the recent statistics data, that is, mean, variance, and coefficient of variation of material, and proposed the strength reduction factors of 0.9 and 0.85 for flexural and shear, respectively, which are equal to or greater than those of 0.9 and 0.75 presented in ACI318-14. This is, as previously mentioned, because the uncertainties are reduced due to a decrease in the variation of the material and member strengths and an enhanced accuracy of their strength estimation. Thus, a more reasonable strength reduction factor, which is on the safe side, was proposed by setting higher $\beta_{t}$.

In accordance with the recent researches, the target reliability for shear in PHC slabs was set to 3.5 in this study. The strength reduction factor for the shear and torsion in RC members is 0.75 in ACI318-14, which applies equally to PHC slabs. As mentioned previously, because PHC slabs are mostly manufactured in a factory, the quality of materials and members is consistently good, and the uncertainties of the member strengths are relatively small compared to typical RC members. In addition, the PHC slab members have hollowcores in the section and relatively small depths, compared to the typical PSC beam members, and thus they have different deviations of the material and member strengths from those PSC beams. Therefore, a detailed analysis is necessary to check the suitability of 0.75 as the strength reduction factor for the shear design of PHC slabs when they are designed by applying the shear strength equations used for the general PSC members.

3.1. Shear Failure Probability of PHC Slabs. In order to investigate whether it is appropriate to apply the shear strength reduction factor of 0.75 in calculating the shear strengths of PHC slabs, the reliability index $(\beta)$ was estimated for 155 data pieces collected in this study, based on the First-Order Reliability Method [30]. For the load combination of $1.2 D+$ $1.6 L$, the nominal strength $\left(\phi R_{n}\right)$ should be designed to be equal to or greater than the required strength $\left(Q_{1.2 D+1.6 L}\right)$, which can be expressed as follows:

$$
\phi R_{n} \geq Q_{1.2 D+1.6 L}
$$

where the safety factor (SF) can be defined as follows:

$$
\mathrm{SF}=\frac{(1.2 D+1.6 L) / \phi}{D+L}
$$

Considering $D+L$ in (18) as the load at shear failure of the specimen, the limit state function $(g)$ can be defined as follows:

$$
g=\mathrm{SF} \cdot V_{n}-V_{\text {test }}<0
$$

where $V_{n}$ is the shear strength calculated by the code equations or other proposed equations by researchers and $V_{\text {test }}$ is the experimental value. The shear strength $\left(V_{n}\right)$ of the PHC slab is a function of several random variables. As shown in (11), that is, the ACI code equation, the compressive strength of concrete $\left(f_{c}^{\prime}\right)$, the compressive stress in concrete at the centroid of the cross section $\left(f_{p c}\right)$, and the shape of the PHC slab $\left(b_{w}, d_{p}\right)$ are the random variables. The moment of inertia of gross section $\left(I_{g}\right)$ and section modulus $(Q)$ can be additional random variables in Eurocode (see (5)). The bias factors and COVs for each random variable refer to the study of Nowak and Szerszen [18] as shown in Table 2. Since $f_{p c}$ is 
TABLE 2: Statistical parameters for variables $[18,19]$.

\begin{tabular}{|c|c|c|c|c|}
\hline Parameters & $\begin{array}{l}\text { Nominal value } \\
\quad(\mathrm{MPa})\end{array}$ & Bias factor & $\mathrm{COV}$ & Distribution \\
\hline \multirow{5}{*}{$f_{c k}$} & 48 & 1.19 & 0.115 & Normal \\
\hline & 55 & 1.09 & 0.090 & Normal \\
\hline & 62 & 1.16 & 0.100 & Normal \\
\hline & 69 & 1.13 & 0.115 & Normal \\
\hline & 83 & 1.04 & 0.105 & Normal \\
\hline$f_{p e}$ & - & 0.9 & 0.16 & Normal \\
\hline$b_{w}$ & - & 1.00 & 0.06 & Normal \\
\hline$d_{p}$ & - & 1.00 & 0.06 & Normal \\
\hline
\end{tabular}

TABLE 3: Summary of shear strength ratios.

\begin{tabular}{lccr}
\hline $\begin{array}{l}\text { Standards and } \\
\text { authors }\end{array}$ & $\begin{array}{c}\text { Mean } \\
\left(V_{c w, \text { Cal }} / V_{c w, \text { Test }}\right)\end{array}$ & Standard deviation & COV \\
\hline Eurocode 2 & 1.111 & 0.290 & 0.260 \\
FIP recommendation & 1.185 & 0.293 & 0.247 \\
JSCE & 1.104 & 0.291 & 0.263 \\
AASHTO-LRFD & 0.600 & 0.153 & 0.255 \\
ACI 318-05 & 0.955 & 0.239 & 0.251 \\
ACI 318-08 & 0.735 & 0.281 & 0.383 \\
Walraven and Mercx & 0.913 & 0.227 & 0.249 \\
Lee et al. & 0.710 & 0.175 & 0.246 \\
(simplified equation) & & & \\
\hline
\end{tabular}

a function of the combinations of several random variables, such as the effective prestress $\left(f_{p e}\right)$, sectional area of tendon $\left(A_{p s}\right)$, and sectional area of the PHC slab $\left(A_{g}=b_{w} d_{p}\right)$, this study assumed a normal distribution of these variables $\left(f_{p e}\right.$, $\left.b_{w}, d_{p}\right)$ and then generated $1.0 \times 10^{6}$ random numbers for each random variable through a Monte Carlo simulation to determine the COV and bias factor of $f_{p c}$. The First-Order Reliability Method (FORM) analysis was performed using the limit state function presented in (19) and the probability distribution of the influencing variables on the shear strength, based on which the reliability index $(\beta)$ was calculated for all the specimens. In case the limit state function is linear, $\beta$ can be estimated by calculating the minimum distance between the origin and the limit state function in a plane where each random variable $\left(X_{1}, X_{2}\right)$ is changed to standard normal distribution random variables $\left(X_{1}^{\prime}, X_{2}^{\prime}\right)$ as shown in Figure 4. That is, the point that orthogonally comes in contact with the limit state function is the most probable failure point (MPP), and the distance between the origin and the $\operatorname{MPP}(\beta)$ can be expressed as a function of the mean and variance of each random variable as follows [30]:

$$
\beta=\frac{\mu_{X_{1}}-\mu_{X_{2}}}{\sqrt{\sigma_{X_{1}}^{2}+\sigma_{X_{2}}^{2}}}
$$

When the limit state function is nonlinear, it is very difficult to calculate the $\beta$ value, and it can be thus simplified by the first-order approximation. The limit state function can be expanded by the Taylor series, as follows:

$$
\begin{aligned}
g\left(X_{1}, X_{2}, \ldots, X_{n}\right)= & g\left(x_{1}^{*}, x_{2}^{*}, \ldots, x_{1}^{*}\right) \\
& +\sum_{i=1}^{n}\left(X_{i}-x_{i}^{*}\right)\left(\frac{\partial g}{\partial X_{i}}\right) \\
& +\sum_{j=1}^{n} \sum_{i=1}^{n} \frac{\left(X_{i}-x_{i}^{*}\right)\left(X_{j}-x_{j}^{*}\right)}{\left(\partial g / \partial X_{i} \partial X_{j}\right)} \\
& +\cdots,
\end{aligned}
$$

where $g$ is a limit state function, $X_{i}$ is a random variable, and $x_{i}^{*}$ is a random variable at the MPP. By the FORM, the firstorder term of (21) can be taken as follows:

$$
g\left(X_{1}, X_{2}, \ldots, X_{n}\right)=\sum_{i=1}^{n}\left(X_{i}^{\prime}-x_{i}^{\prime *}\right)\left(\frac{\partial g}{\partial X_{i}^{\prime}}\right)
$$

where $X_{i}^{\prime}$ and $x_{i}^{\prime *}$ are reduced variates and taken as follows, respectively:

$$
\begin{gathered}
X_{i}^{\prime}=\frac{X_{i}-\mu_{X_{i}}}{\sigma_{X_{i}}}, \\
x_{i}^{\prime *}=\frac{x_{i}^{*}-\mu_{X_{i}}}{\sigma_{X_{i}}} .
\end{gathered}
$$




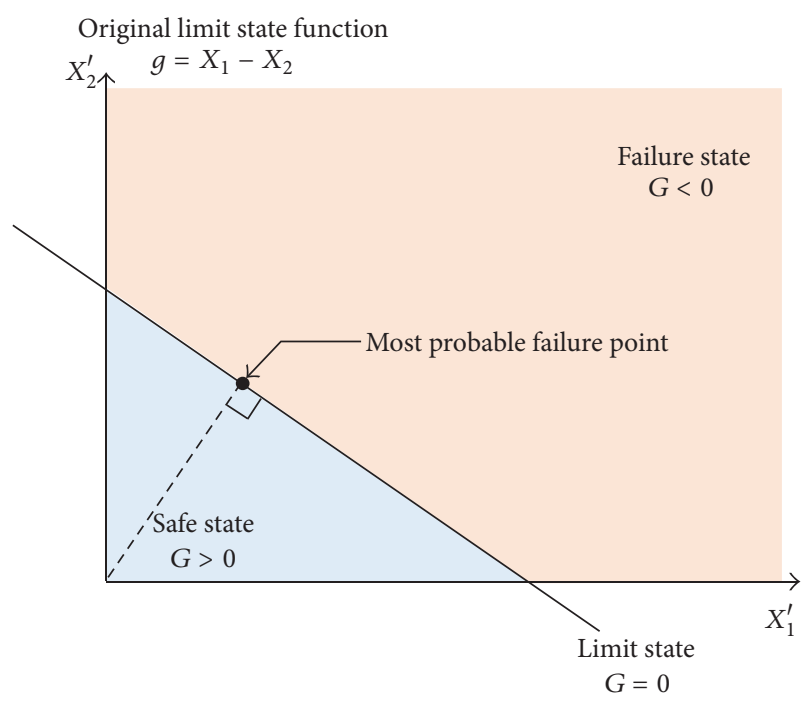

FIgURE 4: Space of reduced variates $X_{1}^{\prime}$ and $X_{2}^{\prime}$.

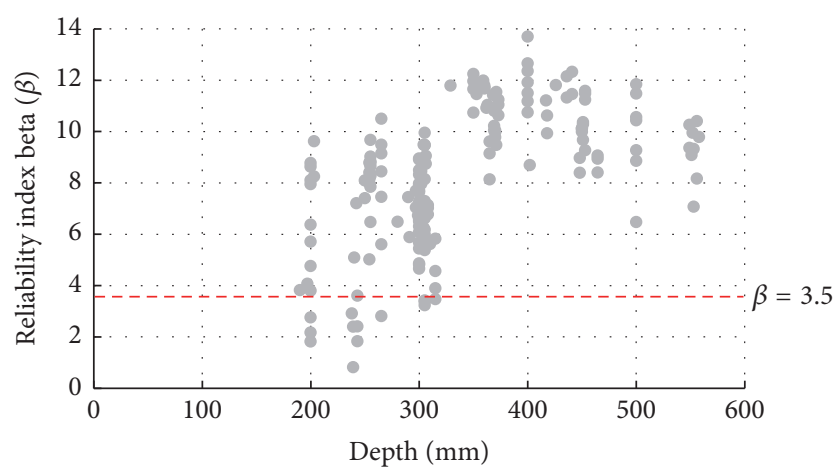

Figure 5: Web-shear strength failure probability of PHC slabs in ACI318-08.

From the first-order approximation, the mean value and variance $\left(\mu_{g}\right.$ and $\left.\sigma_{g}^{2}\right)$ of the function $g(X)$ can be presented, as follows:

$$
\begin{aligned}
& \mu_{g} \approx-\sum_{i=1}^{n} x_{i}^{\prime *}\left(\frac{\partial g}{\partial X_{i}^{\prime}}\right), \\
& \sigma_{g}^{2} \approx \sum_{i=1}^{n}\left(\frac{\partial g}{\partial X_{i}^{\prime}}\right)^{2} .
\end{aligned}
$$

As mentioned previously, the reliability index can be expressed as a function of the mean and standard deviation, and thus the reliability index of FORM becomes

$$
\beta=\frac{\mu_{g}}{\sigma_{g}}=\frac{-\sum_{i=1}^{n} x_{i}^{\prime *}\left(\partial g / \partial X_{i}^{\prime}\right)}{\sqrt{\sum_{i=1}^{n}\left(\partial g / \partial X_{i}^{\prime}\right)^{2}}} .
$$

Figure 5 shows the reliability index $(\beta)$ for 155 specimens, which were calculated by applying the ACI318-08 equation

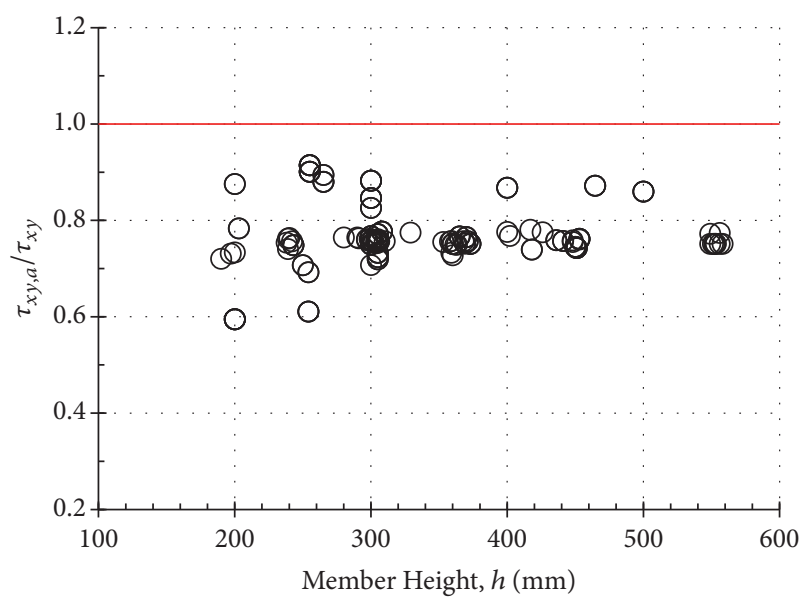

FIGURE 6: Ratio of average shear stress to parabolic shear stress.

to the limit state function with a strength reduction factor of 0.75 and a live load ratio to dead load of 0.5 . The ACI31808 equation showed significantly greater reliability index values in the cases of the PHC members with more than $315 \mathrm{~mm}$ depth because it allows only half the shear strengths of the members, and it confirms that the shear strengths by the ACI318-08 equation are excessively conservative for those thick members. Therefore, the shear strength reduction factor of 0.75 for the thick PHC slabs could result in a very uneconomical design. In addition, there were many cases that did not satisfy the target reliability $\left(\beta_{t}=3.5\right)$ in the PHC members with less than $315 \mathrm{~mm}$ depth. This is because the ACI318-08 equation is based on the assumption of the average shear stress distribution as shown in (10), and thus, as shown in Figure 6, the shear strength is underestimated by about $80 \%$ compared to the shear strength obtained by assuming the parabolic distribution of shear stress on the web. In contrast, as shown in Figure 7, the shear strength by Lee et al.s [9] and Walraven and Mercx's [14] models in which the shear stress distribution of the PHC slab is considered to be a parabolic was found to secure the reliability index more than the target reliability $\left(\beta_{t}\right)$ for most PHC slab members including the members with more than $315 \mathrm{~mm}$ depth. In Lee et al.s [9] and Walraven and Mercx's [14] models, however, the reliability index values $(\beta)$ for most of the data were greater than 4.5 , which means that the failure probability is lower than $3.4 \times 10^{-4} \%$. Therefore, if the PHC slabs are designed by these approaches, the shear strength reduction factor of 0.75 could result in a very uneconomical design.

3.2. Shear Strength Reduction Factor for PHC Slabs. This study derived the relationship between the strength reduction factor of the PHC slab and reliability index $(\beta)$ by using the shear strength estimation model proposed by the authors' previous study [9]. In order to consider various load conditions applied to the structures, as shown in Figure 8, the reliability indexes $(\beta)$ were calculated according to the ratio of the dead load to the sum of dead load and live load $(D /(D$ $+L)$ ). The load ratios $D /(D+L)$ ranged from 0.9 , in which 


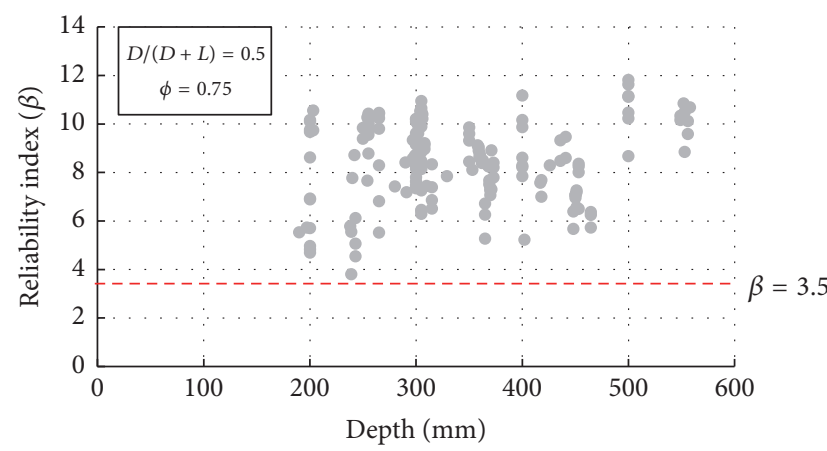

(a) Lee et al. (2014)

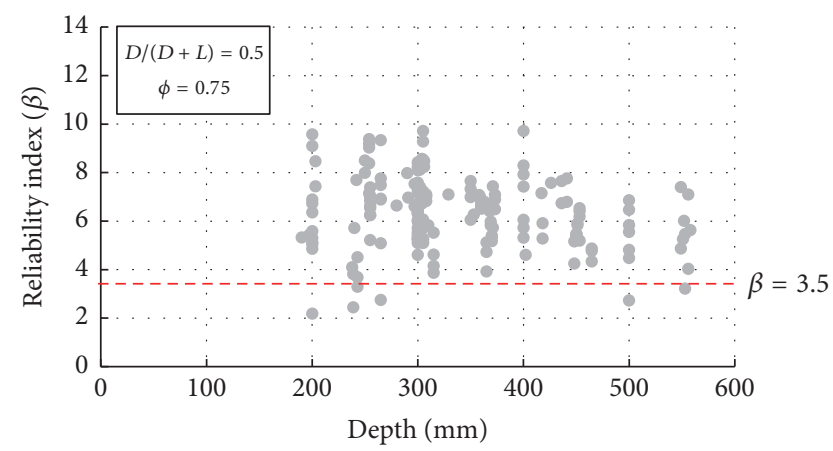

(b) Walraven and Mercx (1983)

FIGURE 7: Reliability index values of PHC slabs.

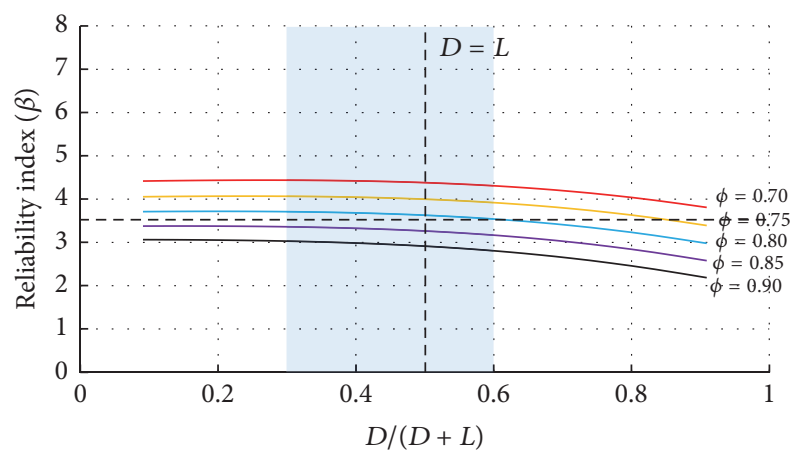

FIGURE 8: Reliability index for Lee et al.s model.

the live load is very small, to 0.09 where the live load is very large. The reliability index $(\beta)$ is expressed as follows:

$$
\beta=\frac{\mu_{\text {Lee }}-\mu_{D}-\mu_{L}}{\sqrt{\sigma_{\text {Lee }}^{2}+\sigma_{D}^{2}+\sigma_{L}^{2}}},
$$

where $\mu_{\text {Lee }}$ and $\sigma_{\text {Lee }}$ are the mean and variance of Lee et al.s model, respectively. In this study, a normal distribution was assumed for the variables used in Lee et al's model and $1.0 \times$ $10^{6}$ random numbers were then generated for each random variable through the Monte Carlo simulation to determine the COV and bias factor $(\lambda)$ of Lee et al's model. The sectional and material properties of PHC slabs were referred from Im tests shown in Table 1, and their bias factors and COVs were referred from Nowak and Szerszen [18] as shown in Table 2. In (26), $\mu_{D}$ and $\mu_{L}$ are the mean values of the dead and live loads, respectively, and $\sigma_{D}^{2}$ and $\sigma_{L}^{2}$ are the variances of the dead and live loads, respectively. The statistical data for the loads used in this study is also based on the study by Nowak and Szerszen [18] as presented in Table 4 . The mean values of $\mu_{\text {Leee }}, \mu_{D}$, and $\mu_{L}$ can be expressed as follows:

$$
\begin{gathered}
\mu_{\text {Lee }}=\lambda_{\text {Lee }} R, \\
\mu_{D}=\lambda_{D} D, \\
\mu_{L}=\lambda_{L} L,
\end{gathered}
$$

TABLE 4: Statistical parameters for loads $[18,19]$

\begin{tabular}{lccc}
\hline Load component & Bias & COV & Distribution \\
\hline Dead load & 1.03 & 0.08 & Normal \\
Live load & 1.00 & 0.18 & Normal \\
\hline
\end{tabular}

where $\lambda_{\text {Lee }}, \lambda_{D}$, and $\lambda_{L}$ are the bias factors of Lee et al's model, dead loads, and live loads, respectively. By using (17) and the ratios of dead load to dead load plus live load $(D /(D+L))$, (26) can be rearranged as a function of $\mu_{D}$.

When the dead load and live load are the same (i.e., $D /(D+L)=0.5)$, if the shear strength reduction factor of 0.75 is used, the reliability index was about 4.0 , which is on the safe side. For the strength reduction factor of 0.8 , the reliability index was about 3.5 which is almost equal to the target reliability $\left(\beta_{t}\right)$. According to Nowak and Szerszen $[18,19]$, the load ratio $D /(D+L)$ was reported to range generally from 0.3 to 0.7 in beams, from 0.3 to 0.6 in slabs, and from 0.4 to 0.9 in columns. Therefore, when the strength reduction factor of 0.75 is applied for the cases of load ratios ranging from 0.3 to 0.6 , which is typical in slabs, the reliability index $(\beta)$ ranges from 3.90 to 4.07 , which means being very safe. When the strength reduction factor of 0.8 is applied, the reliability index $(\beta)$ ranges from 3.51 to 3.71 , which is slightly greater than the target reliability index $\left(\beta_{t}\right)$. This suggests that the use of the strength reduction factor of 0.8 makes it possible to perform an economic design, while satisfying the target reliability index. As mentioned previously, however, a large number of results of ACI318 equation do not satisfy the target reliability index $\left(\beta_{t}\right)$ for the members with less than $315 \mathrm{~mm}$ depth; thus, it is desirable to slightly lower the shear strength reduction factor for the design of the PHC slabs based on ACI318-08.

\section{Conclusion}

This study evaluated the accuracy on the web-shear strength equations of various codes and researchers by comparing to the experimental results of PHC slabs failed in web-shear and examined the shear strength reduction factors suitable for 
the shear design of the PHC slabs. The following conclusions were obtained from this study.

(1) The reliability analysis showed that the ACI318-08 equation is excessively conservative for the PHC members with greater than $315 \mathrm{~mm}$ depth; the shear strength reduction factor of 0.75 for the thick PHC slabs could result in a very uneconomical design.

(2) The ACI318-08 equation did not satisfy the target reliability $\left(\beta_{t}=3.5\right)$ for the PHC slabs with less than $315 \mathrm{~mm}$ depth, and thus it is desirable to slightly lower the shear strength reduction factor for the design of the PHC slabs based on ACI318-08.

(3) The models by Walraven and Mercx and Lee et al. provided a good accuracy on the shear strengths of PHC slabs, but they provided very conservative results when the shear strength reduction factor of 0.75 was used.

(4) The reliability analysis of Lee et al.s shear strength equation showed that the strength reduction factor of 0.8 works well, leading to an economic design, while satisfying the target reliability index.

\section{Conflicts of Interest}

The authors declare that they have no conflicts of interest.

\section{Acknowledgments}

This research was supported by Basic Science Research Program through the National Research Foundation of Korea (NRF) funded by the Ministry of Education (2016R1D1A3B03932214).

\section{References}

[1] R. J. Becker and D. R. Buettner, "Shear Tests of Extruded Hollow-Core Slabs," PCI Journal, vol. 30, no. 2, pp. 40-54, 1985.

[2] D. R. Buettner and R. J. Becker, PCI Manual for the Design of Hollow-Core Slabs, Precast/Prestressed Concrete Institute, ILLINOIS, Chicago, 2nd edition, 1998.

[3] N. M. Hawkins and S. K. Ghosh, "Shear strength of hollow-core slabs," PCI Journal, vol. 51, no. 1, pp. 110-115, 2006.

[4] ACI Committee 318, Building Code Requirements for Structural Concrete (ACI 318-05) and Commentary, American Concrete Committee, Farmington Hills, MI, USA, 2005.

[5] ACI Committee 318, Ed., Building Code Requirements for Structural Concrete (ACI 318-08) and Commentary, American Concrete Committee, Farmington Hills, MI, USA, 2008.

[6] K. D. Palmer and A. E. Schultz, "Factors affecting web-shear capacity of deep hollow-core units," PCI Journal, vol. 55, no. 2, pp. 123-146, 2010.

[7] J. H. Im, Web shear strength of prestressed hollow-core slab [Ph.D. thesis], University of Seoul, 2015.

[8] K. D. Palmer and A. E. Schultz, "Experimental investigation of the web-shear strength of deep hollow-core units," PCI Journal, vol. 56, no. 4, pp. 83-104, 2011.
[9] D. H. Lee, M.-K. Park, J.-Y. Oh, K. S. Kim, J.-H. Im, and S.Y. Seo, "Web-shear capacity of prestressed hollow-core slab unit with consideration on the minimum shear reinforcement requirement," Computers and Concrete, vol. 14, no. 3, pp. 211-231, 2014.

[10] AASHTO LRFD Bridge Design Specifications, American Association of State Highway and Transportation Officials, Washington, DC, USA, 4th edition, 2007.

[11] European Committee for Standardization (CEN), Eurocode 2: Design of Concrete Structure. Part 1-1: General Rules and Rules for Buildings, EN 1992-1-1:2004, Brussels, 2004.

[12] FIP Recommendations, Precast Prestressed Hollow Core Floors: FIP Commission on Prefabrication, London, UK, 1988.

[13] Concrete Committee of JSCE, Ed., Standard Specifications for Concrete Structures Design, Japan Society of Civil Engineers, Tokyo, Japan, 2007.

[14] J. C. Walraven and W. P. M. Mercx, "The Bearing Capacity of Prestressed Hollow-Core Slabs," Heron, vol. 28, no. 3, pp. 1-4, 1983.

[15] J. G. Macgregor, S. A. Mirza, and B. Ellingwood, "Statistical analysis of resistance of reinforced and prestressed concrete members," ACI Journal, vol. 80, no. 16, pp. 167-176, 1983.

[16] ACI Committee 318, "Building code requirements for reinforced concrete (ACI 318-56) and commentary," American Concrete Committee, 2014.

[17] TNO Building and Constructions Research, TNO Report: Standard Shear Tests on Prestressed Hollow Core Slabs according to EN 1168, TNO Building and Constructions Research, Hague, 2005.

[18] A. S. Nowak and M. M. Szerszen, "Calibration of design code for buildings (ACI 318): part 1 - statistical models for resistance," ACI Structural Journal, vol. 100, no. 41, pp. 377-382, 2003.

[19] M. M. Szerszen and A. S. Nowak, "Calibration of design code for buildings (ACI 318): part 2 - reliability analysis and resistance factors," ACI Structural Journal, vol. 100, no. 42, pp. 383-391, 2003.

[20] M. P. Collins and D. Mitchell, Prestressed Concrete Structures, Prentice Hall, 1991.

[21] D. A. Kuchma, N. M. Hawkins, S.-H. Kim, S. Sun, and K. S. Kim, "Simplified shear provisions of the AASHTO LRFD bridge design specifications," PCI Journal, vol. 53, no. 3, pp. 53-73, 2008.

[22] D. H. Lee, S.-J. Han, and K. S. Kim, "Dual potential capacity model for reinforced concrete beams subjected to shear," Structural Concrete, vol. 16, no. 3, pp. 443-456, 2016.

[23] G. Bertagnoli and G. Mancini, "Failure analysis of hollow-core slabs tested in shear," Structural Concrete, vol. 10, no. 3, pp. 139152, 2009.

[24] M. Pajari, "Resistance of prestressed hollow core slabs against web shear failure," Research Notes 2292, Technical Research Centre of Finland (VTT), Espoo, Finland, 2005.

[25] M. Pajari, "Web shear failure in prestressed hollow core slabs," Journal of Structural Engineering, vol. 42, no. 4, pp. 207-217, 2009.

[26] A. C. Ugural and S. K. Fenster, Advanced strength and applied Elasticity, Prentice Hall, 2003.

[27] J. G. Macgregor, "Load and Resistance Factors for Concrete Design," ACI Journal, vol. 80, no. 27, pp. 279-287, 1983.

[28] M. Mayer, "Die Sicherheit der Bauwerke und ihre Berechnung nach Grenzkräften anstatt nach zulassigen Spannungen," J. Springer, vol. 66, 1962. 
[29] A. M. Freudenthal, "The Safety of Structure," ASCE Transactions, vol. 112, pp. 383-391, 1947.

[30] A. H. Ang and W. H. Tang, Probability Concepts in Engineering Planning and Design, Wiley, 1990.

[31] P. Chetchotisak, J. Teerawong, S. Yindeesuk, and J. Song, "New strut-and-tie-models for shear strength prediction and design of RC deep beams," Computers and Concrete, vol. 14, no. 1, pp. 19-40, 2014. 

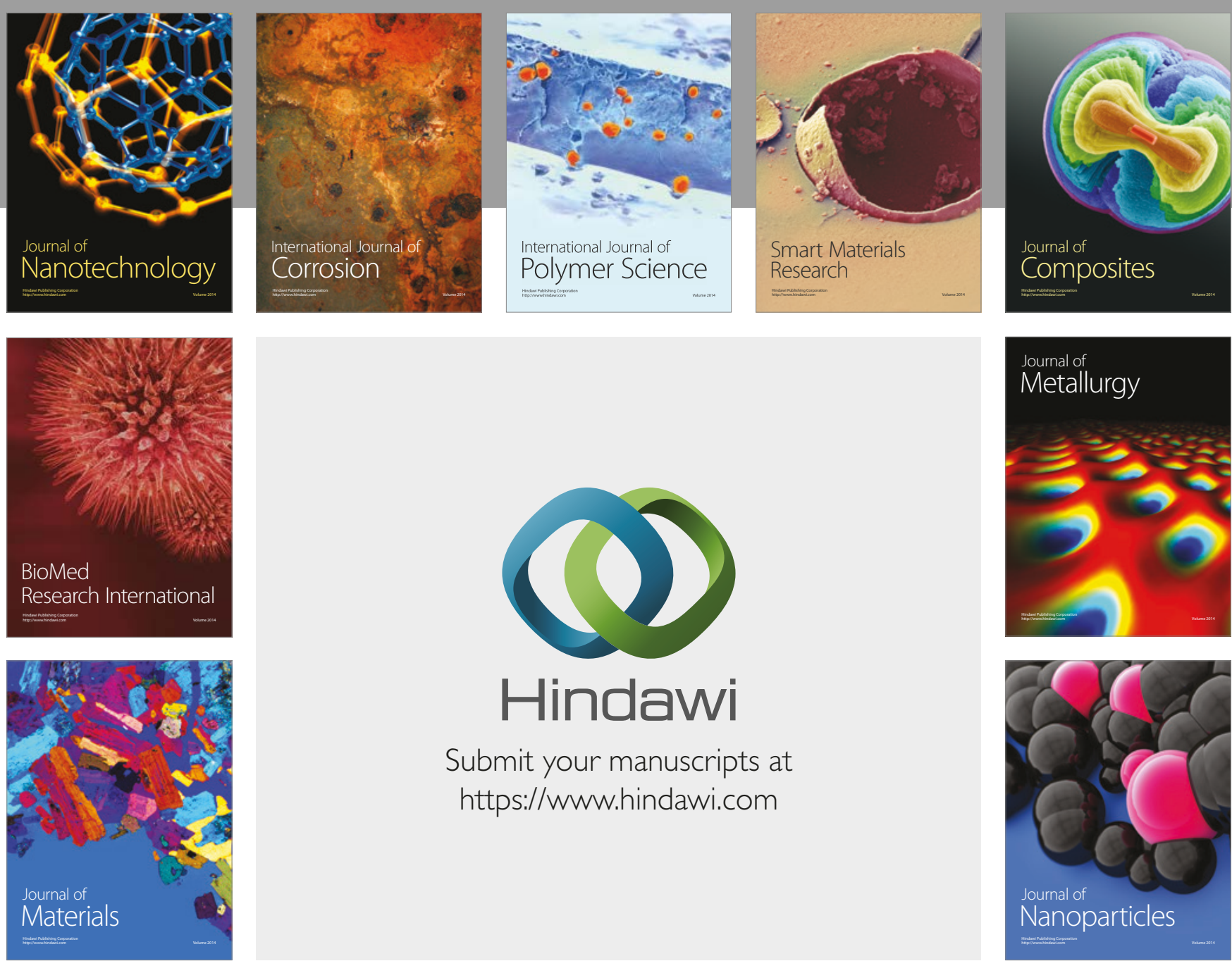

\section{Hindawi}

Submit your manuscripts at

https://www.hindawi.com
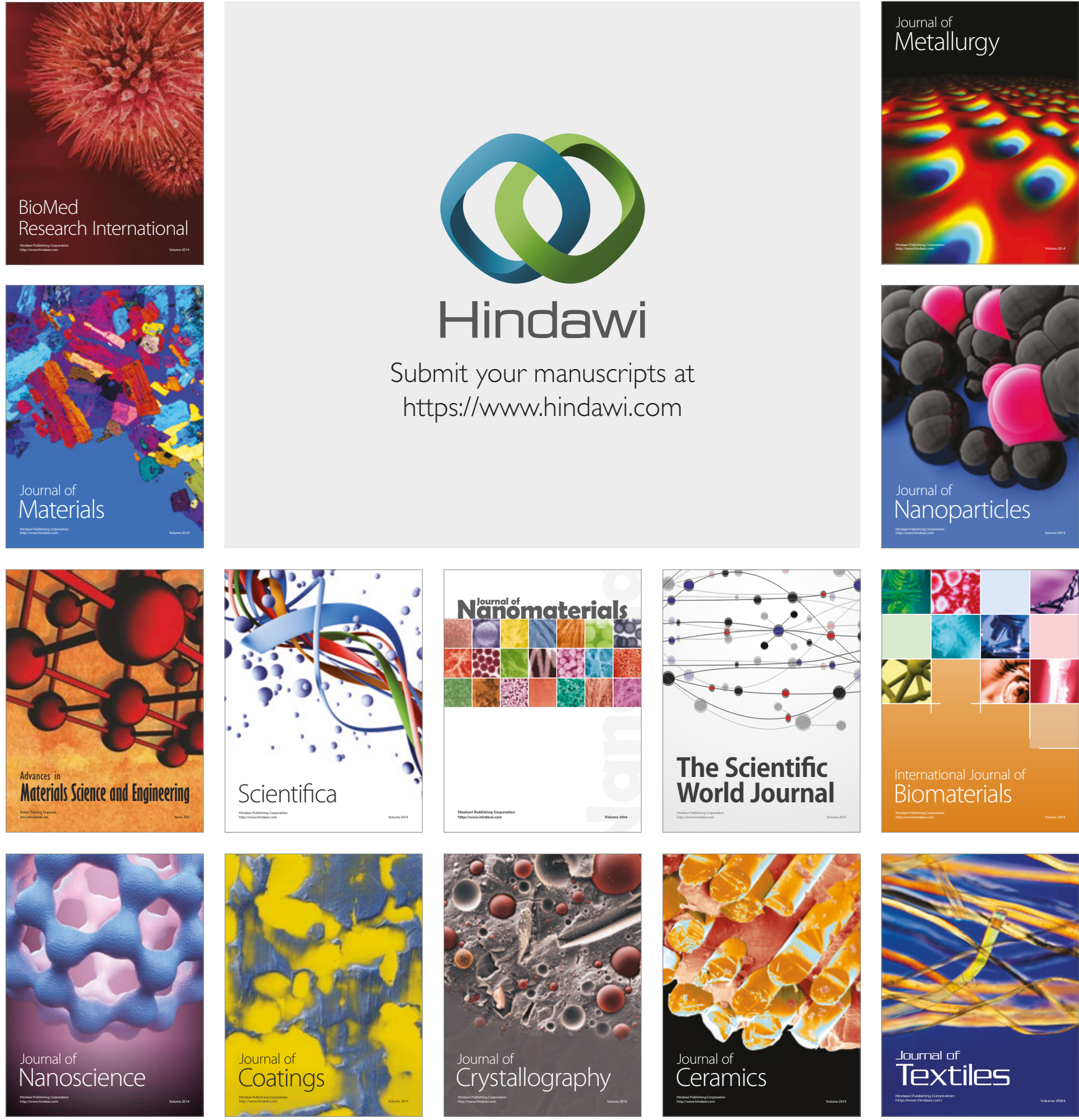

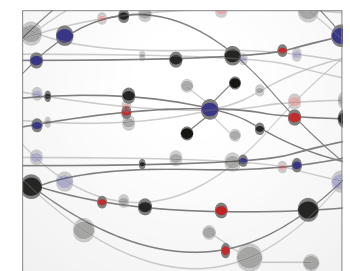

The Scientific World Journal
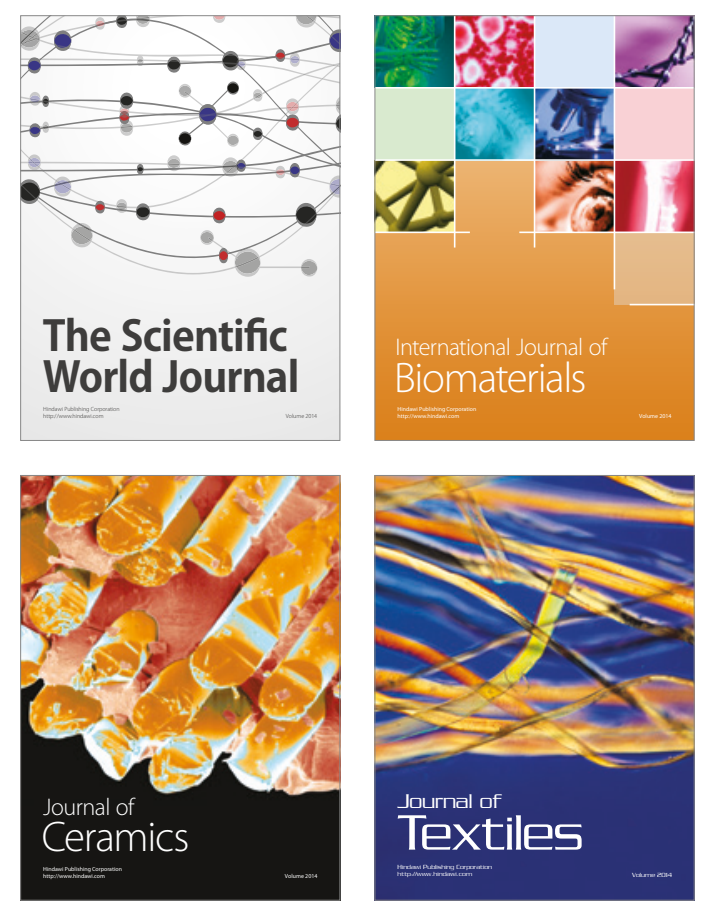